\title{
A linear model for leaf area measurement to screen potential leaf material for herbal drug in Adhatoda vasica $\mathrm{L}$.
}

\author{
J. V. Thaker, R. P. Kuvad and V. S. Thaker* \\ Saurashtra University, Rajkot- 360005 (Gujarat), INDIA \\ *Corresponding author. E-mail: casprogramme@gmail.com \\ Received: September 23, 2015; Revised received: December 4, 2015; Accepted: February 3, 2016
}

Centre for Advanced Studies in Plant Biotechnology and Genetic Engineering, Department of Biosciences,

\begin{abstract}
Leaf area is an important parameter in physiology and agronomy studies. Linear models for leaf area measurement are developed for plant species as a nondestructive method. The plant Adhatoda vasica L. (a medicinal plant) was selected and the leaves of this plant were used for development of linear model for leaf area using Leaf Area Meter (LAM) software. Planimetric parameters (length, length ${ }^{2}$, width and width ${ }^{2}$ ) and gravimetric (dry weight and water content) parameters are considered for the development of linear model for this plant species. Single factor ANOVA and linear correlations were worked out using these parameters and leaf area. The plant was showed significant relationship with the parameters studied. The best correlation as represented by regression coefficient $\left(R^{2}\right)$ was used and improved $R^{2}$ is worked out. It is observed that with increase in leaf area, water content is also increased and showed best correlation with the leaf area. Thus water content can be taken as a parameter for developing linear model for leaf area is concluded.
\end{abstract}

Keywords: Adhatoda vasica L., Gravimetric parameters, Leaf area, Planimetric parameters, Regression coefficient

\section{INTRODUCTION}

Adhatoda vasica belonging to family Acanthaceae, commonly known as Adosa, is a small, evergreen shrub found many regions of India and throughout the world, with a multitude of uses in traditional Ayurveda (Gangwar and Ghosh, 2014). Leaves are large and lance-shaped. Stem is herbaceous above and woody below. Leaves opposite and exstipulate. Flower spikes or panicles, small irregular zygomorphic, bisexual, and hypogynous (Shinwari and Shah, 1995). The leaves, flowers, fruit and roots are extensively used for treating cold cough, whooping cough, chronic bronchitis and asthma, as sedative, expectorant and antispasmodic (Pandita et al., 1983). The vast variety of pharmacological uses of Adhatoda is believed to be the result of its rich concentration of alkaloids (Shrivastava et al., 2006; Maikhuri and Gangwar, 1965). Adhatoda vasica used for its anti-asthmatic and bronchodilator activity (Lahiri and Pradhan, 1964), wound healing activity (Bhargava et al., 1988), antiulcer activity (Shrivastava et al., 2006), anti allergy activity (Wagner, 1989), anti bacterial activity (Patel and Venkatakrishna, 1984), cholagogue activity ( $\mathrm{Rabinovich} \mathrm{et} \mathrm{al.,} 1966$ ), antitubercular activity (Narimaian et al., 2005), insecticidal activity (Srivastava et al., 2006) and abortifacient and uterotonic activity (Claeson et al., 2000). This plant has great potential to be developed as drug pharmaceutical industries. However, herbal formulations are often questioned for its consistency mainly because of less care is taken in antidote preparations. Physiologically active compounds may vary with age and conditions of the leaves; therefore, there must be some guide lines for the collection of the materials. Leaf area of the plants not only determines the photosynthetic capacity but can be use as a morphological marker for collection of medicinally important materials (Kuvad et al., 2014; Tatmiya et al., 2014). Leaf area of the plants is correlated with leaf dimensions like length and width and linear models are developed as nondestructive method. Further, gravimetric parameters like leaf dry weight and water content can also be used to build linear model for leaf area (Daughtry, 1990). Leaf area (LA) is an important variable for most ecophysiological studies in terrestrial ecosystems concerning light interception, evapotranspiration, photosynthetic efficiency, fertilizers, irrigation response and plant growth (Blanco and Folegatti, 2003) and hence also to maintain herbal drug farms with efficient practices. Therefore, in this study, a linear model for leaf area measurement is developed for Adhtoda vasica plant which can be useful for leaf harvest for the best pharmaceutical preparations.

\section{MATERIALS AND METHODS}

Collection of the samples: The plant material (leaves) of $A$. vasica was collected from the botanical garden of Department of Biosciences, Saurashtra University, 
Table 1. Regression analysis between leaf area and gravimetric/planimetric parameter of Adhatoda vasica L.

\begin{tabular}{cccccc}
\hline Parameter & $\mathrm{Y}$ & $\mathrm{R}^{2}$ & $\mathrm{R}$ & OBSàLAC $^{2}$ & $\mathrm{R}$ \\
\hline $\mathrm{DW}$ & $\mathrm{y}=11701 \mathrm{x}+1223$ & Gravimetric parameter & & \\
\hline $\mathrm{WC}$ & $\mathrm{y}=5666 . \mathrm{x}+534.5$ & $\mathrm{R}^{2}=0.824$ & 0.907 & $\mathrm{R}^{2}=0.841$ & 0.917 \\
\hline \multicolumn{7}{c}{ Planimetric parameter } & 0.952 & $\mathrm{R}^{2}=0.979$ & 0.989 \\
\hline $\mathrm{L}$ & $\mathrm{y}=144.5 \mathrm{x}-3133$ & $\mathrm{R}^{2}=0.826$ & 0.908 & $\mathrm{R}^{2}=0.806$ & 0.897 \\
$\mathrm{~L}^{2}$ & $\mathrm{y}=1.371 \mathrm{x}+458.6$ & $\mathrm{R}^{2}=0.862$ & 0.928 & $\mathrm{R}^{2}=0.985$ & 0.992 \\
$\mathrm{~W}$ & $\mathrm{y}=444.0 \mathrm{x}-2954$ & $\mathrm{R}^{2}=0.803$ & 0.896 & $\mathrm{R}^{2}=0.819$ & 0.904 \\
$\mathrm{~W}^{2}$ & $\mathrm{y}=12.61 \mathrm{x}+711.9$ & $\mathrm{R}^{2}=0.801$ & 0.984 & $\mathrm{R}^{2}=0.958$ & 0.979 \\
\hline
\end{tabular}

Note: $\mathrm{n}=$ Number of leaf $(130) ; \mathrm{DW}=$ Dry Weight; $\mathrm{WC}=$ Water Content; $\mathrm{L}=$ Length; $\mathrm{L}^{2}=$ Length Square; W= Width; $\mathrm{W}^{2}=$ Width Square; OBS= Observed value; $\mathrm{LAC}=$ Leaf Area Calculated.

Rajkot $\left(22.30^{\circ} \mathrm{N}, 70.78^{\circ} \mathrm{E}\right)$, Gujarat, India. Nearly 130 leaves were taken for this study.

Measurement of leaf area: Collected leaves are washed thoroughly under running tap water and blotted over filter papers. Each individual leaf/leaflets were scanned and saved as .bmp file. The scanned leaf is weighed before and after oven drying at $80{ }^{\circ} \mathrm{C}$ for constant weight. The difference in fresh and dry weight is considered as water content. Maximum width (W) and length of mid rib (L) was measured. All data tabulated for $\mathrm{L}, \mathrm{L}^{2}, \mathrm{~W}, \mathrm{~W}^{2}$, water content (WC) and dry weight (DW). Each individual leaf/leaflets was scanned and saved as .bmp files then proceed for leaf area measurement as per the software standard protocol (Kuvad et al., 2014; Tatmiya et al., 2014). The present method of leaf area measurement is very simple, rapid as software (LAM) is very efficient and user friendly (http://btm.gujarat.gov.in/btm/bitvirtual-init. $\mathrm{htm})$. This software measures different parameter of leaf (leaf area, length of midrib and width of leaf) similar measurements can be done using image $\mathrm{J}$ software (O'neal et al., 2002).

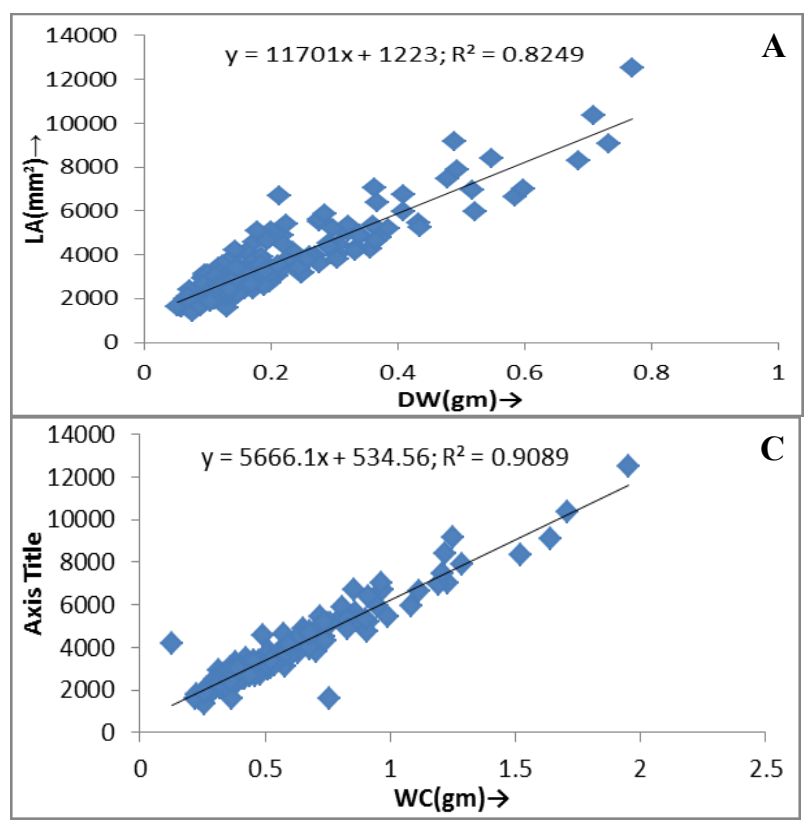

Statistical Analysis: All collected data were subjected to correlation analysis like single factor ANOVA and linear correlations between leaf area and planimetric or gravimetric parameters using Excel software (MS office, Microsoft).

\section{RESULTS AND DISCUSSION}

In this study, Gravimetric parameters (WC and DW) and Planimetric parameters $\left(\mathrm{L}, \mathrm{L}^{2}, \mathrm{~W}\right.$ and $\left.\mathrm{W}^{2}\right)$ are worked out for correlation analysis showed significant variations (Table 1). All $\mathrm{R}^{2}$ were statistically significant, therefore the improved $\mathrm{R}^{2}$ were taken into consideration. Although all regression equations for improved values were calculated, linear model was given for the better relationship on the basis of $\mathrm{R}^{2} \mathrm{ob}$ tained. Regression analysis of $A$. vasica plant with gravimetric and planimetric parameters is presented in table-1 (Figs. 1 -3). Data on leaf area and DW showed statistically significant relationship $\mathrm{R}^{2}=0.824$ which improved to $\mathrm{R}^{2}=0.841$ (Figs. 1A and B). Data on WC showed $\mathrm{R}^{2}=0.908$ which improved to $\mathrm{R}^{2}=0.979$ when regression equation of first set of data is used to test

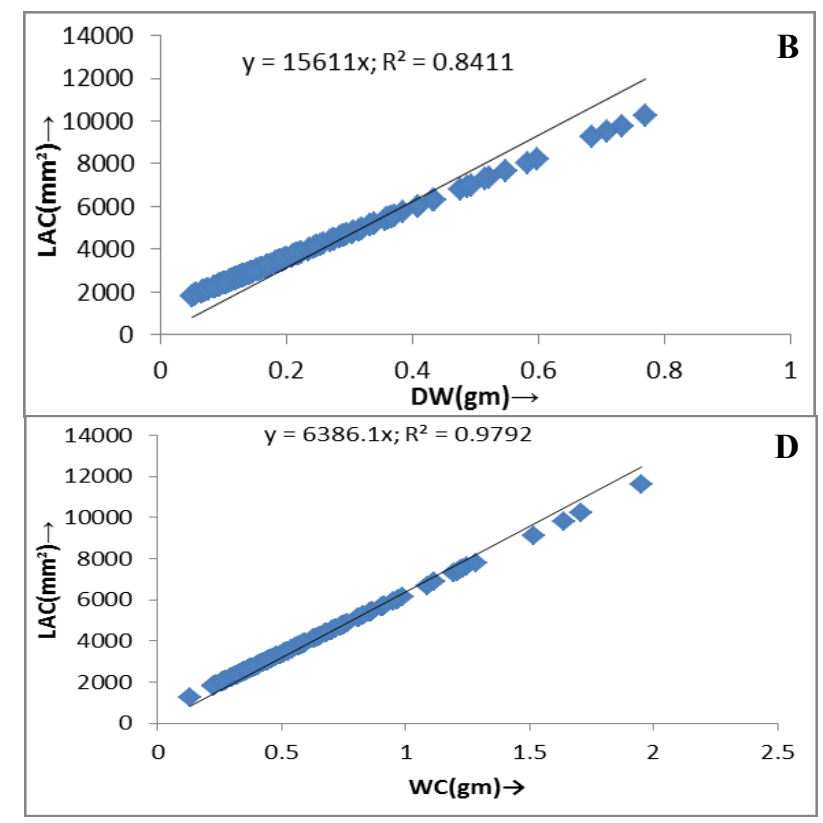

Fig.1. (A) Leaf area versus dry weight. (B) Calculated value of leaf area versus observed value of dry weight. (C) Leaf area versus water content. (D) Calculated value of leaf area versus observed value of water content. 

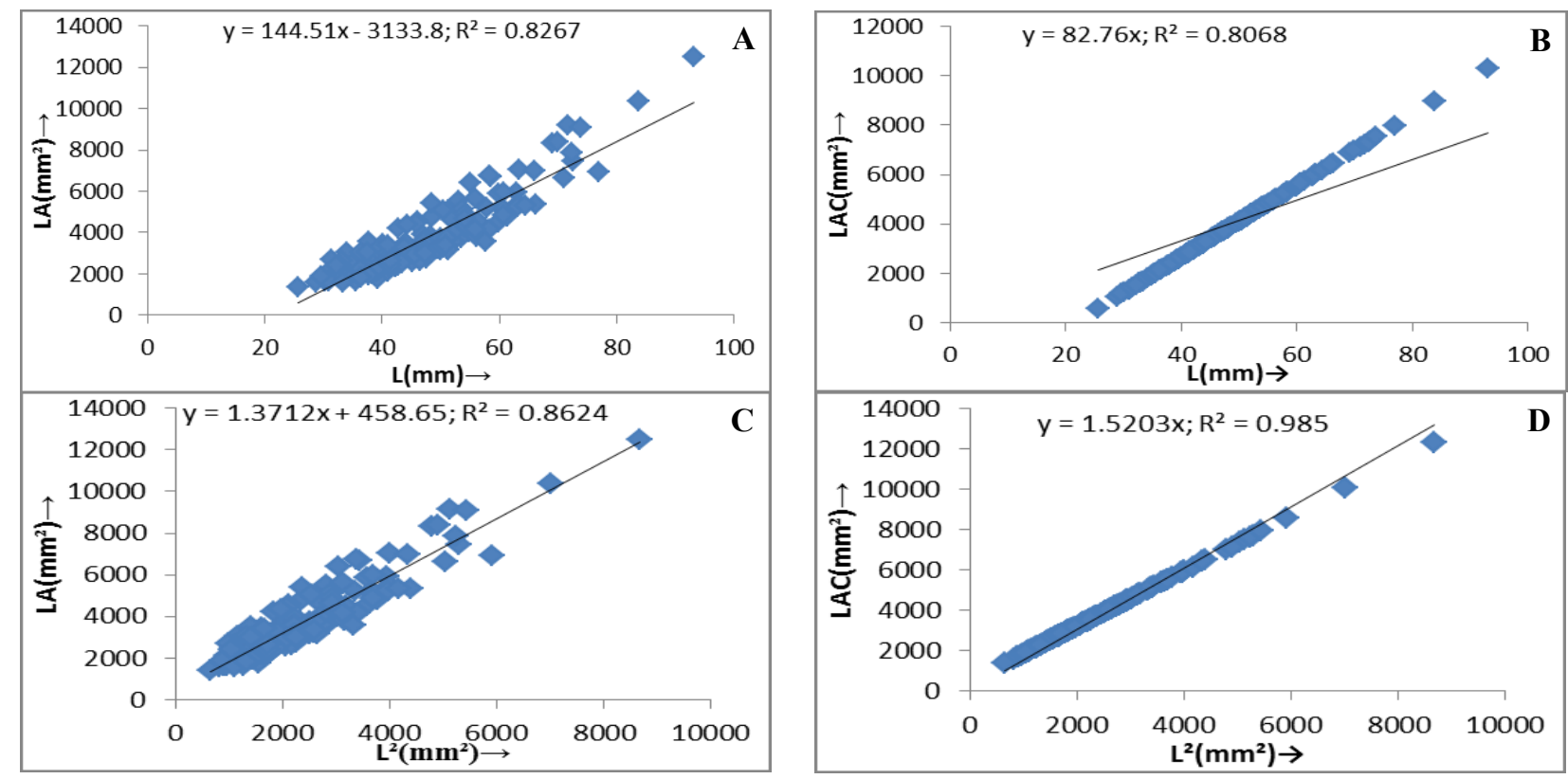

Fig.2. (A) Leaf area versus midrib length. (B) Calculated value of leaf area versus observed value of midrib length. (C) Leaf area versus midrib length square. (D) Calculated value of leaf area versus observed value of midrib length square.
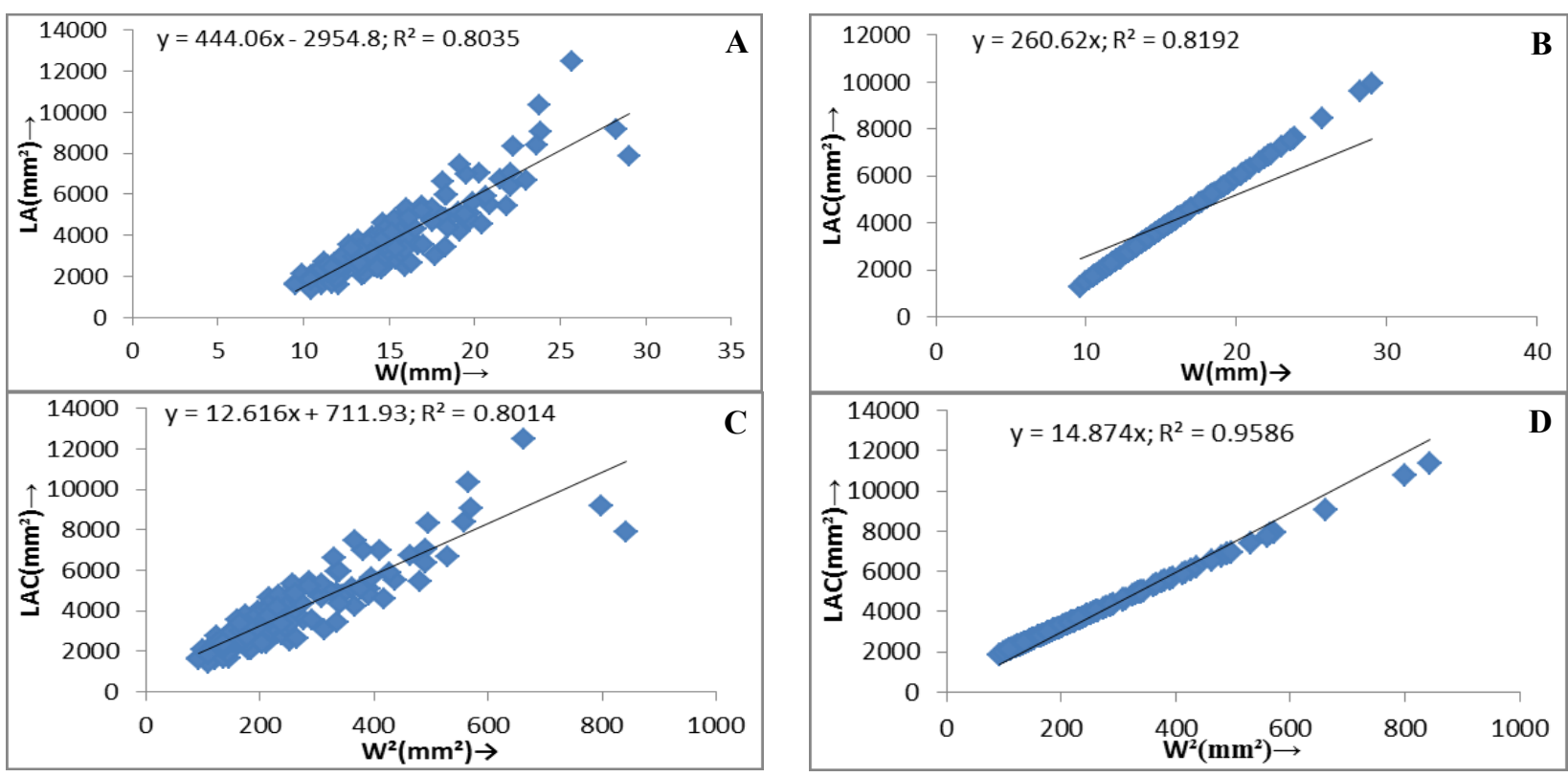

Fig.3. (A) Leaf area versus leaf width. (B) Calculated value of leaf area versus observed value of leaf width. (C) Leaf area versus leaf width square. (D) Calculated value of leaf area versus observed value of leaf width square.

the linear model (Figs. $1 \mathrm{C}$ and D).

In gravimetric parameter WC found to be better correlated with leaf area than DW (Fig. 1). When planimetric parameter $\mathrm{L}$ and $\mathrm{L}^{2}$ were correlated with LA, L ${ }^{2}$ was better correlated (Figure 2). Regression equation $\mathrm{y}=144.5 \mathrm{x}-3133\left(\mathrm{R}^{2}=0.826\right)$ for $\mathrm{L}$ showed no change relationship or less value for $R^{2}=0.806$. Data on $\mathrm{L}^{2}$ showed $\mathrm{R}^{2}=0.862$ which improved to $\mathrm{R}^{2}=0.985(\mathrm{n}=130)$. Similarly data on $\mathrm{W}$ correlated with LA plotted in Figure 3 showed $R^{2}=0.803$ which improved to $\mathrm{R}^{2}=0.819$. Data on $\mathrm{W}^{2}$ showed $\mathrm{R}^{2}=0.801$ which improved to $\mathrm{R}^{2}=0.958$. Thus data on $\mathrm{L}^{2}$ are better correlated in planimetric parameter.
Water content is also considered as one of the important parameters to study since in many experiments performed in our lab or elsewhere suggests importance of water in expansion growth (Egli and Tekrony, 1997; Rabadia et al., 1999). It is assumed that increase in the size of the leaf may also increase in water content at least up to certain level, the level where leaf size stabilized. Indeed, when gravimetric parameters are considered, we found good correlation with water amount and leaf area in $A$. vasica (Figs. 1C and D, Table 1). Similarly, in planimetric parameters; it is best explained by $\mathrm{L}^{2}$ in $A$. vasica (Figs. $2 \mathrm{C}$ and $\mathrm{D}$, Table 1). The $\mathrm{R}^{2}$ of planimetric parameter was less as 
compared to gravimetric. Linear model of these parameters were tested with the leaves of another field which showed improved relationship. Water content is known to play an important role in cell expansion in numbers of the tissues (Egli and Tekrony, 1997; Jhala and Thaker, 2015); it also showed relationship with leaf area in the present study $\left(\mathrm{R}^{2}=0.908\right)$ and the relationship observed more as compared to dry weight $\left(\mathrm{R}^{2}=0.824\right)$. In many studies, were gravimetric parameters are taken for consideration; dry weight is reported as a considerable measured (Dingkuh., 1996, Folkard et al., 1999; Wilson et al., 2001; Young et al., 2007). However, for A. vasica water content was closely related with leaf area than dry weight. Since amount of the water is highly correlated with size of the organs in the study reported above, and in our results suggests that the water content can be taken as a one of the parameter for determination of leaf area by linear model. Additionally our study reported that the water content is statistically more significant than dry weight.

\section{Conclusion}

It is suggested that water content per leaf can be considered for development of linear model in A. vasica plant since it is more statistically significant than any other parameter in $A$. vasica plant. The results on leaf area can be used as guidelines for the harvest of $A$. vasica plant for effective pharmaceutical preparations.

\section{REFERENCES}

Bhargava, M.K., Singh, H. and Kumar, A. (1988). Evaluation of Adhatoda vasica as a wound healing agent in buffaloes. Clinical, mechanical and biochemical studies. Indian Veterinary Journal, 65(1): 33.

Blanco, F.F. and Folegatti, M.V. (2003). A new method for estimating the leaf area index of cucumber and tomato plants. Horticultura Brasileira, 21 (4): 666-669.

Claeson, U.P., Malmfors, T., Wikman, G. and Bruhn, J.G. (2000). Adhatoda vasica: a critical review of ethnopharmacological and toxicological data. Journal of Ethnopharmacology, 72: 1 .

Daughtry, C.S.T. (1990). Direct measurement of canopy structure Instrumentation for studying vegetation canopies for remote sensing in optical and thermal infrared regions. Goel MS; Nnorman JM (Ed.) Harwood Academic, New York, pp 45-60.

Dingkuhn, M. (1996). Modeling concepts for the phenotypic plasticity of dry matter and nitrogen partitioning in rice. Agricultural Systems, 52: 383-397.

Egli, D.B. and Tekrony, D.M. (1997). Species differences in seed water status during seed maturation and germination. Seed Science Research, 7: 3-11.

Folkard, A., Abdoulaye, S. and Michael, D. (1999). Reserve mobilization, dry matter partitioning and specific leaf area in seedlings of African rice cultivars differing in early vigor. Field Crops Research, 62: 191-202.

Gangwar, A.K. and Ghosh, A.K. (2014). Medicinal uses and pharmacological activity of adhatoda vasica. International journal of herbal medicine, 2(1): 88-91.

Jhala, V.M. and Thaker, V.S. (2015). X-ray computed tomo- graphy to study rice (Oryza sativa L.) panicle development. Journal of Experimental Botany, 66(21): 68196825.

Kuvad, R.P., Chudasama, K.S., Jhala, V.M. and Thaker, V.S. (2014). Standardization of leaf age for radical scavenging activity in Terminalia Arjuna. Journal of Applied Nature Science, 6(1): 76-80.

Lahiri, P.K. and Pradhan, S.N. (1964). Pharmacological investigation of vasicinol, an alkaloid from Adhatoda vasica Nees. Indian Journal of Experimental Biology, 2: 219.

Maikhuri, R.K. and Gangwar, A.K. (1965). Ethnobiological notes on the Khasi and Garo tribes of Meghalaya, Northeast India. Economic Botany, 47: 345.

Narimaian, M., Badalyan, M., Panosyan, V., Gabrielyan, E., Panossian, A. and Wikman, G. (2005). Randomized trial of a fixed combination (KanJang) of herbal extracts containing Adhatoda vasica, Echinacea purpurea and Eleutherococcus senticosus in patients with upper respiratory tract infections. Phytomedicine, 12(8): 539-47.

O’Neal, M.E., Landis, D.A. and Rufus, I. (2002). An inexpensive, accurate method for measuring leaf area and defoliation through digital image analysis. Journal Economy Entomology, 95(6): 1190-1194.

Pandita, K., Bhatia, M.S., Thappa, R.K., Agarwal, S.G., Dhar, K.L. and Atal, C.K. (1983). Seasonal variation of alkaloids of Adhatoda vasica and detection of glycosides and $\mathrm{N}$-oxides of vasicine and vasicinone. Planta Medica, 48: 81-82.

Patel, V.K. and Venkatakrishna, B.H. (1984). In vitro study of antimicrobial activity of Adhatoda vasika Linn. (leaf extract) on gingival inflammation a preliminary report. International Journal of Medical Science, 38(4): 70-2.

Rabadia, V.S., Thaker, V.S. and Singh, Y.D. (1999). Relationship between water content and growth of seed and fiber in three cotton cultivars. Journal of Agronomy and Crop Science 183, 255-261.

Rabinovich, M.I., Leskov, A.I. and Gladkikh, A.S. (1966). Cholegogic properties of peganine. Vrachei, pp181.

Shinwari, Z.K. and Shah, M. (1995). The Ethnobotany of Kharan district, Balochistan, Pakistan. Proc Sym Med $P l, 12: 35-38$.

Shrivastava, N., Shrivastava, A., Banerjee, A. and Nivsakar, M. (2006), Anti-ulcer activity of Adhatoda vasica Nees. Journal of Herbal Pharmacotherapy, 6(2): 43-9.

Tatmiya, R.N., Chudasama, K.S., Jhala, V.M. and Thaker, V.S. (2014). Screening of proper leaf size in Centella asiatica for antioxidant potential and separation of phenolics using RP-HPLC. Journal of Applied Pharmacological Science, 4 (2): 043-047.

Wagner, H. (1989). Search for new plant constituents with potential antiphlogistic and antiallergic activity. Planta Medica, 55(3): 235-41.

Wilson, K.B., Hanson, P.J., Mulholland, P., Baldocchi, D.D. and Wullschleger, S. (2001). A comparison of methods for determining forest evapotranspiration and its components: sap flow, soil water budget, eddy covariance and catchment water balance. Agricultural and Forest Meteorology, 106: 153-168.

Young, Y.C., Sungbong, O., Myoung, M.O. and Jung, E.S. (2007). Estimation of individual leaf area, fresh weight, and dry weight of hydroponically grown cucumbers (Cucumis sativus L.) using leaf length, width, and SPAD value. Scientia Horticulturae, 111: 330-334. 